\title{
Cephradine Intercalated Mg-Al Layered Double Hydroxide
}

\author{
Md. Ashaduzzaman ${ }^{1,}$, Nashid Kaisher Riyadh ${ }^{1}$, Nusrat Mustary ${ }^{2}$, \\ Sayed Md. Shamsuddin ${ }^{1}$
${ }^{1}$ Department of Applied Chemistry and Chemical Engineering, Faculty of Engineering and Technology, University of Dhaka, Dhaka 1000, Bangladesh
${ }^{2}$ Department of Community Medicine, National Institute of Preventive and Social Medicine University, Dhaka-1000 \\ (NIPSOM), Faculty of Preventive and Social Medicine, Bangabandhu Sheikh Mujib Medical
}

*Corresponding author: E-mail: azaman01@du.ac.bd

Keywords: Intercalation, Mg-AI LDH, cephradine, spectroscopy, SEM

\begin{abstract}
Engineered advanced functional materials are promising candidates for biotechnology and biomedical science. Mg-Al layered double hydroxide (LDH), anionic or hydrotalcite-like clays consist of positively charged layers and exchangeable anions along with water molecules in the interlayer space were synthesized from homogeneous solution of $\mathrm{MgCl}_{2}$ and $\mathrm{AlCl}_{3}$ by urea induced co-precipitation method. A pharmaceutically important drug, cephradine was intercalated with synthesized LDH in alkali media $(\mathrm{pH} \mathrm{10)}$ by in-situ technique. Characterizations of the products were carried out using Attenuated Total Reflectance Infra-red (ATR-IR), Energy Dispersive X-ray (EDX) and X-ray Diffraction (XRD) spectroscopy. Scanning electron morphological images envisaged a distinct crystalline and amorphous phases of Mg-Al LDH before and after modification with cephradine. Intercalation of bioactive molecules with LDH would enhance their stability providing sustained release behavior in physiological environment.
\end{abstract}

\section{Introduction}

Advanced inorganic functional materials, particularly of layered double hydroxide (LDH)type are attracting increasing interest lately due to their versatile multifunctional applications. LDH compound consists of brucite-like sheets, in which divalent cations are partially replaced by trivalent cations [1-3]. Consequently, the layers become positively charged and the counter anions are needed to balance these charges. The counter anion can subsequently be replaced by other anions through various procedures.

Generally, the intercalation of anion can be accomplished by various routes such as direct coprecipitation [4,5] method, or exchange process [6-8]. In the former method, the LDH is contacted with a solution of the guest anion to be intercalated while in the latter method addition of a mixed $\mathrm{M}^{2+}$ and $\mathrm{M}^{3+}$ solution to a basic solution of the anion have to be done. In the rehydration method, calcined LDH is contacted with a solution containing the anion followed by aging [4]. Coprecipitation method is the most widely accepted to synthesize LDHs in which a mixed alkaline solution is added to a mixed salt solution and the resultant slurry is aged at a desired temperature. For both ion-exchange and co-precipitation methods, physicochemical and structural properties of the resulting materials depend on the precipitation $\mathrm{pH}$, temperature, ageing time, washing and drying conditions [9-11]. Some reported work showed that different methods of preparation produce materials with different physicochemical properties [12,13].

Works on the intercalation of the various organic molecules into the hydroxide layers have been exploited for various purposes and application [14,15] in many different areas such as bioactive agent [10], medicine [15,16,17], catalyst [18], anti-inflammatory drugs, [19,20,21] urea biosensor and supports [22], and decolorizing agents [23]. The production and use of drug must be controlled to minimize the potential damage to the environment and public health. An effective way is to design smart formulations, which combines the optimum bioactivity and minimum amount of drug. The use of controlled release formulations of drug will restrict their movement through other 
organ and prevent cross-contamination and side effects. Similarly several synthetic cationic surfactants, organic polymers, natural plant lignin and starch materials have been proposed as supporting agents for pesticides in the formulations [24]. Some studies on herbicides-intercalated $\mathrm{Mg} / \mathrm{Al}$ layered double hydroxide ( $\mathrm{LDH})$ synthesized by direct, regeneration and ion exchange methods show slow release property $[25,26]$. This is due to the fact that the loading capacity of LDH mainly depends on its charge density and layered structure. The charge density of hydroxide sheets in LDHs is in the range of $0.33-0.25 \mathrm{Cm}^{-2}$ (as high as in mica, $0.32-0.34 \mathrm{Cm}^{-2}$ ) [27], which is much higher compared to that observed in various cationic clays of both natural and synthetic origin. However, the remarkable behavior of LDH is their high reactivity toward various organic anions, which can exchange as much as $80-100 \%$ of the interlayer anions in LDHs [27].

In this work we attempted to intercalate a pharmaceutical drug, cephradine into Mg-Allayered double hydroxide by direct co-precipitation with simultaneous anion exchange.

\section{Experimental}

\section{Materials}

Aluminum chloride (hexa-hydrate) (MW: $241.43 \mathrm{~g} / \mathrm{mol}$, assay: 97.0\%, Techno Pharma Chem, Haryana, India), magnesium chloride (hexa-hydrate), (MW: $203.31 \mathrm{~g} / \mathrm{mol}$, assay: 98.0\% Unichem), manganese chloride (tetra-hydrate), (MW: $197.92 \mathrm{~g} / \mathrm{mol}$, assay: 99.0\%, Uni-chem) and urea (MW: $60.06 \mathrm{~g} / \mathrm{mol}$, assay: 99.0\%, Merck, India) were used as received. Cephradine (MW: 349.40) was purchased from Fluka and was used without further purification.

\section{Methods}

\section{Co-precipitation of Mg-Al-LDH}

LDH's were prepared by co-precipitation from a homogeneous aqueous solution of $\mathrm{Mg}^{2+}$ and $\mathrm{Al}^{3+}$ with urea as a precipitating agent. At first, an aqueous salt solution of $\mathrm{Al}^{3+}$ and $\mathrm{Mg}^{2+}$ with the molar fraction $\mathrm{Al}^{3+} /\left(\mathrm{Al}^{3+}+\mathrm{Mg}^{2+}\right)$ equal to 0.33 was prepared by dissolving $\mathrm{AlCl}_{3}$ and $\mathrm{MgCl}_{2}$ in distilled water. To this solution solid urea was added until the molar fraction of urea/ $\left(\mathrm{Mg}^{2+}+\mathrm{Al}^{3+}\right)$ reaches 3.3.Then the clear solution was refluxed for 36 hours. LDH was precipitated as a white mass, filtered, and washed until chloride free, and then dried in an atmospheric drier at $60^{\circ} \mathrm{C}$ till constant weight. Highly crystalline Mg-Al-LDH with narrow particle size was obtained. The conditions chosen for the synthesis provides $\mathrm{Mg}-\mathrm{Al}-\mathrm{LDH}$ with ' $\mathrm{x}$ ' around 0.33, i.e. the composition is more likely represented by $\mathrm{Mg}_{0.67} \mathrm{Al}_{0.33}(\mathrm{OH}) 2\left(\mathrm{CO}_{3}\right)_{0.165} 0.4 \mathrm{H}_{2} \mathrm{O}$ [22].

\section{Characterization}

\section{Attenuated Total Reflectance Infrared (ATR-IR) spectroscopy}

Spectra (4000-400 $\left.\mathrm{cm}^{-1}\right)$ were collected to determine the chemical bonds of polymers after polymerization by ATR-IR spectroscopy. Attenuated total reflection (ATR) method involves pressing the sample against a high-refractive-index prism and measuring the infrared spectrum using infrared light that is totally internally reflected in the prism. A zinc selenide (ZnSe) prism is used in the ATR accessory. The instrument used was a Shimadzu Prestige 21, single bounce foundation series ATR accessory and a $45^{\circ}$ angle of incidence. Each spectrum was obtained by cumulating 32 scans at a resolution of $4 \mathrm{~cm}^{-1}$.

\section{XRD, EDX and SEM techniques}

The X-ray diffraction (XRD) was carried out to analyze the phase and estimate the lattice space between Mg-Al- LDH using X-ray diffractometer (XRD, Bruker D8 Advance, Germany) with $0.15405 \mathrm{~nm} \mathrm{Cu}-\mathrm{K} \alpha$ radiation source in the $2 \theta$ range from $5^{\circ}$ to $70^{\circ}(40 \mathrm{KV}, 40 \mathrm{~mA}$, step size 0.020 , scan rate $0.50 \mathrm{~min}^{-1}$ ). The XRD patterns with diffraction intensity versus $2 \theta$ were recorded. Energy dispersive X-ray (EDX) analysis was carried out with JEOL JSM-7600F for elemental analysis. The surface morphology of the sample was obtained using scanning electron microscopy (SEM) JEOL, JSM-7600F, Japan. 


\section{Results and discussion}

\section{Synthesis of cephradine intercalated Mg-Al-LDH}

At first a procedure for synthesis of $\mathrm{Mg}-\mathrm{Al}-\mathrm{LDH}$ is established according to the published article of Vial et al. [22]. They suggested an excellent technique in presence of urea to facilitate precipitation of $\mathrm{LDH}$ from a homogeneous solution of $\mathrm{MgCl}_{2}$ and $\mathrm{AlCl}_{3}$ salt with refluxing $36 \mathrm{~h}$. The synthesis conditions chosen for $\mathrm{Mg}-\mathrm{Al}-\mathrm{LDH}$ provide with the compositional formula which is expressed by $\mathrm{Mg}_{0.67} \mathrm{Al}_{0.33}(\mathrm{OH})_{2}\left(\mathrm{CO}_{3}\right)_{0.165} 0.4 \mathrm{H}_{2} \mathrm{O}$ [22].

Since the cephradine consists of one carboxylic acid functional group, an aqueous alkali medium ( $\mathrm{pH}$ 10) was chosen to activate the functional group as $-\mathrm{COO}^{-+} \mathrm{Na}$. Besides, this drug also contains two more carboxyl functional group which presents the molecule as a negatively charged candidate for the positively charged Mg-Al-LDH. Primarily, we tried to intercalate the drug only stirring the mixture of the solution ay $\mathrm{pH}$ below 7, unfortunately there was no trace of intercalated drug in the LDH compound checked by different instrumental means. This is due to the fact that in acidic $\mathrm{pH}$, cephradine is protonated and becomes positively charged entity which was strongly electrostatically denied by cationic LDH as shown in Fig. 1. Therefore, we changed our way to intercalate the drug and followed an in-situ intercalation process in alkali environment. Cephradine at $\mathrm{pH}>7$ becomes soluble in carboxylate state but due to loss of protons, nitrogen atoms of amines exist with pair of electrons which attract positively charged metallic ions of LDH.

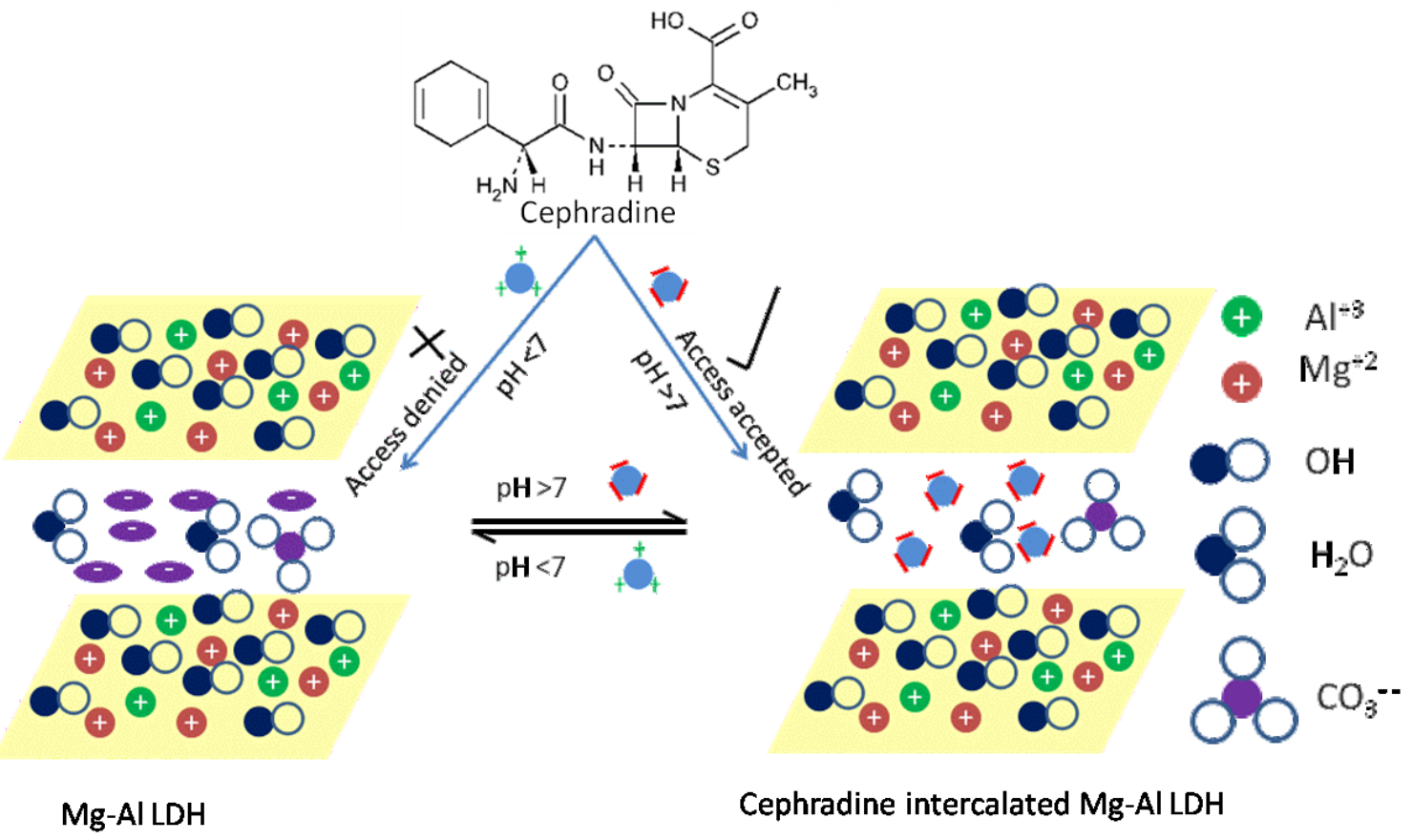

Figure 1. Schematic presentation of mechanism involved in cephradine intercalated Mg-Al-LDH preparation.

\section{ATR-IR spectral analysis}

ATR-IR spectroscopy has been used as an important tool for characterizing molecular structure of cephradine in terms of functional groups by studying the vibration change occurring from the excitation of the bonds. In LDH, ATR-IR is used to determine the presence or absence of target molecules in the interlayer, and to check that LDH layered material matches the expected spectrum. Since functional groups absorb at characteristic frequencies of IR radiation, ATR-IR with higher-quality scans was performed to find detailed information (c.f. to specify the presence or absence of main functional groups in the system, to demonstrate the relative arrangement of the hydroxide layers, and to set the extent of ordering of water in the sample) about the interlayer environment. In addition, we obtain exact information about the distortion that the intercalated molecules underwent by comparing the spectra of the original LDHs with those of the intercalated compounds [28]. 


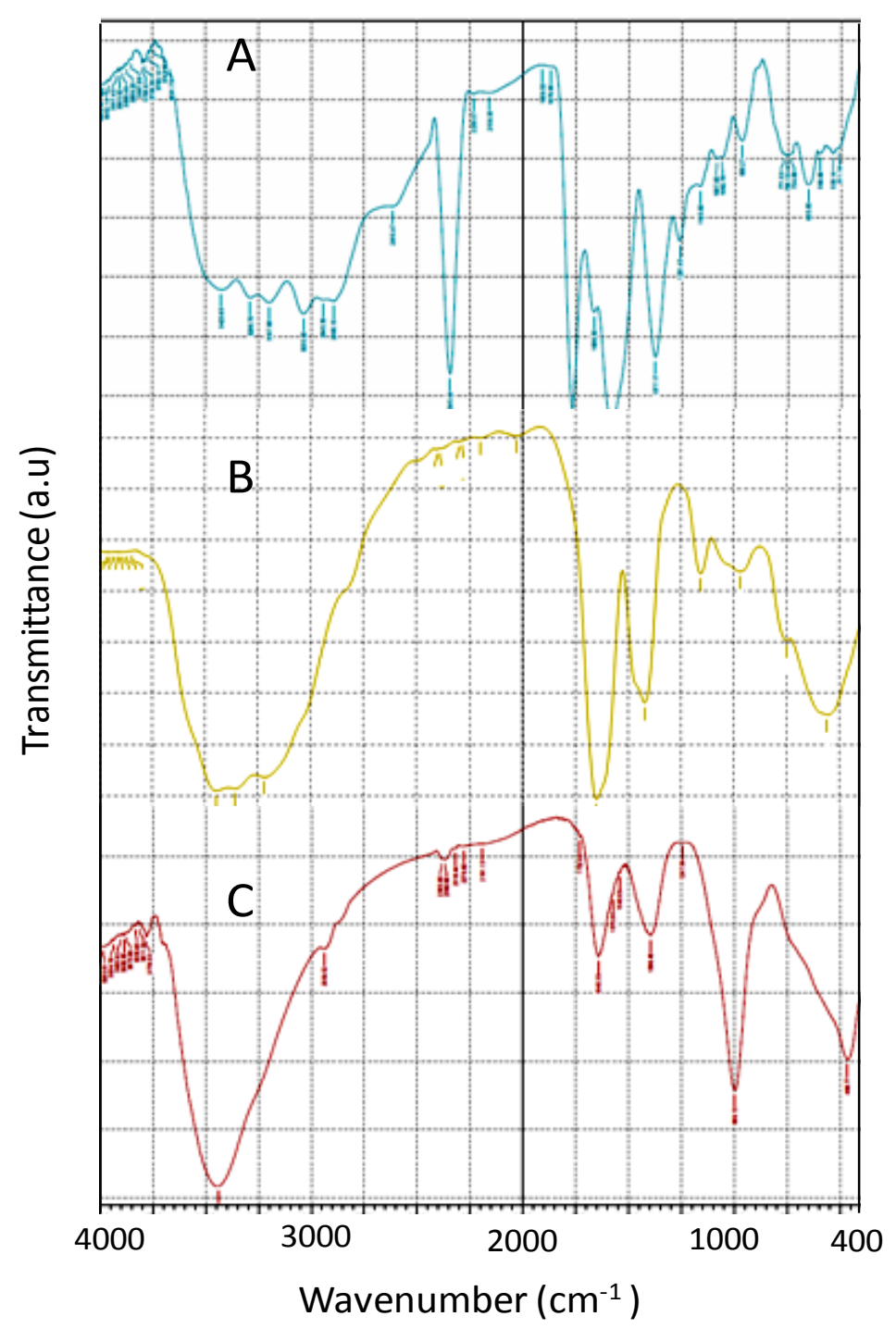

Figure 2. ATR-IR spectrum of cephradine (A) Mg-Al-LDH (B) and cephradine intercalated $\mathrm{Mg}-\mathrm{Al} \mathrm{LDH}$.

The functional groups of cephradine (Fig. 2A) were first confirmed from characteristic peaks at 1766 and $1667 \mathrm{~cm}^{-1}$ recorded for carbonyl $(=\mathrm{C}=\mathrm{O})$ and amide I $\left(-\mathrm{CO}-\mathrm{NH}_{2}\right)$ groups respectively. A sharp peak at $2345 \mathrm{~cm}^{-1}$ was also recognized for $-\mathrm{C}-\mathrm{N}=$ which is present in the main structure of cephradine. The peaks between 2850 and $3000 \mathrm{~cm}^{-1}$ were accounted for C-H stretching of saturated and unsaturated structural positions.

Later we studied the synthesized Mg-Al-LDH compounds after drying at $105{ }^{\circ} \mathrm{C}$. The ATRIR spectra for Mg/Al-LDH (Fig. 2B) showed a broad and strong band in the range $3200-3600 \mathrm{~cm}^{-1}$ centered at $3448 \mathrm{~cm}^{-1}$ which was due to the $\mathrm{O}-\mathrm{H}$ stretching vibration of the inorganic layers and interlayer water molecules. Another common wavenumber for LDH-like material is a band at $1650 \mathrm{~cm}^{-1}$ which is assigned to the bending vibration of interlayer water molecules [29]. For $\mathrm{Mg} / \mathrm{Al}-$ $\mathrm{LDH}$, bands in the lower wavenumber region corresponds to the lattice vibration mode such as the translation vibrations of $\mathrm{Mg}-\mathrm{OH}$ at $750 \mathrm{~cm}^{-1}$ and deformation vibration of $\mathrm{OH}-\mathrm{Mg}-\mathrm{Al}-\mathrm{OH}$ at $575 \mathrm{~cm}^{-1}$ were observed.

IR spectrum in Fig. 2C shows that cephradine was intercalated into the LDH interlayer space. A broad absorption band at around $3400 \mathrm{~cm}^{-1}$ for both nanohybrid arises from the stretching mode of $\mathrm{OH}$ groups in the brucite-like layer and/or physisorbed water [30]. The bands at $1732 \mathrm{~cm}^{-1}$ and $1643 \mathrm{~cm}^{-1}$ for cephradine and LDH are attributed to carboxylate functional group of the intercalated cephradine anion. A band at $1396 \mathrm{~cm}^{-1}$ for both nanohybrids can be attributed to $\mathrm{C}=\mathrm{C}$ bond vibration of the aromatic group. The small peaks at 2343 and $2967 \mathrm{~cm}^{-1}$ attributed to $-\mathrm{CH}$ stretching of cephradine. 


\section{Energy Dispersive X-Ray (EDX) elemental analysis}

Energy Dispersive X-Ray was used for elemental analysis. The elements, carbon, hydrogen, nitrogen, and sulfur (CHNS) presents in a sample were determined as the mass percentage of the intercalated compound where unmodified LDH does not contain most of these elements namely nitrogen and sulfur. The results of the elemental analysis are furnished in the Table 1.

Table 1. Elements of Mg-Al LDH before and after modification with cephradine

\begin{tabular}{lcccccc}
\hline & \multicolumn{7}{c}{ Elements (mass \%) } \\
\cline { 2 - 7 } Type & $\mathrm{Al}$ & $\mathrm{Mg}$ & $\mathrm{C}$ & $\mathrm{O}$ & $\mathrm{N}$ & $\mathrm{S}$ \\
\hline Mg-Al-LDH & 36.16 & 8.63 & 4.73 & 50.48 & 0 & 0 \\
Cephradine - & 33.35 & 6.48 & 10.56 & 46.50 & 1.78 & 1.33 \\
Mg-Al-LDH & & & & & & \\
\hline
\end{tabular}

\section{X-ray Diffraction analysis}

XRD is a very useful tool to characterize crystal in terms of the crystalline structure, lattice parameters, morphology and size where the reflections of LDH crystal are indexed to a hexagonal lattice with rhombohedral 3R symmetry. The cell parameter $c$ (the thickness of one layer consisting of a brucite-like sheet and one interlayer) of LDH is usually estimated as $3 d 003$ or $d 003+2 d 006$ $+3 d 009$, and the cell parameter $a$ (the mean closest metal-metal distance within a layer) can be easily calculated from the 110 reflection $(a=2 d 110)$, where diffraction planes (003), (006), (009) indicate the peaks of LDH from the lower angle to the high angle. We know that XRD measurement follows Bragg's law: $n \mathrm{nj}=2 d \sin \mathrm{lj}$, where $\mathrm{nj}$ is the wavelength of the incident X-ray beam, $d$ is the spacing between each lattice, $\mathrm{l} j$ is the angle between the incident X-ray beam and the reflecting crystal plane, and $n$ is an integer representing the order of the reflection (in practice, taken to be 1) [31].

The XRD patterns of the unmodified and cephradine modified LDH are shown in Fig. 3A and B. As expected, the position of the first order basal reflection $<003>$ in the modified samples is shifted to a higher d-value indicating an expansion in the interlayer distance. Although modified sample did not show distinct reflection at $d=0.76 \mathrm{~nm}$, their existence with a weak and broad reflection in the close vicinity, which may be either due to the crystallinity distortion of original LDH occurred by inserted cephradine molecules or due to a higher order reflection in $<001>$ series in the modified LDH. However, the first statement seems that the XRD pattern of the modified sample show reflections corresponding to single $<001>$ series and no mixed $<h k l>$ as compared to the unmodified Mg-Al-LDH. The disappearance of reflection corresponding to mixed $<h k l>$ series also indicates a loss of crystallinity of $\mathrm{Mg}-\mathrm{Al} \mathrm{LDH}$ after cephradine modification. This may be due to the loss of coherent conditions and/or the presence of only small crystallites for all other directions in the sense of scattering [31]. 


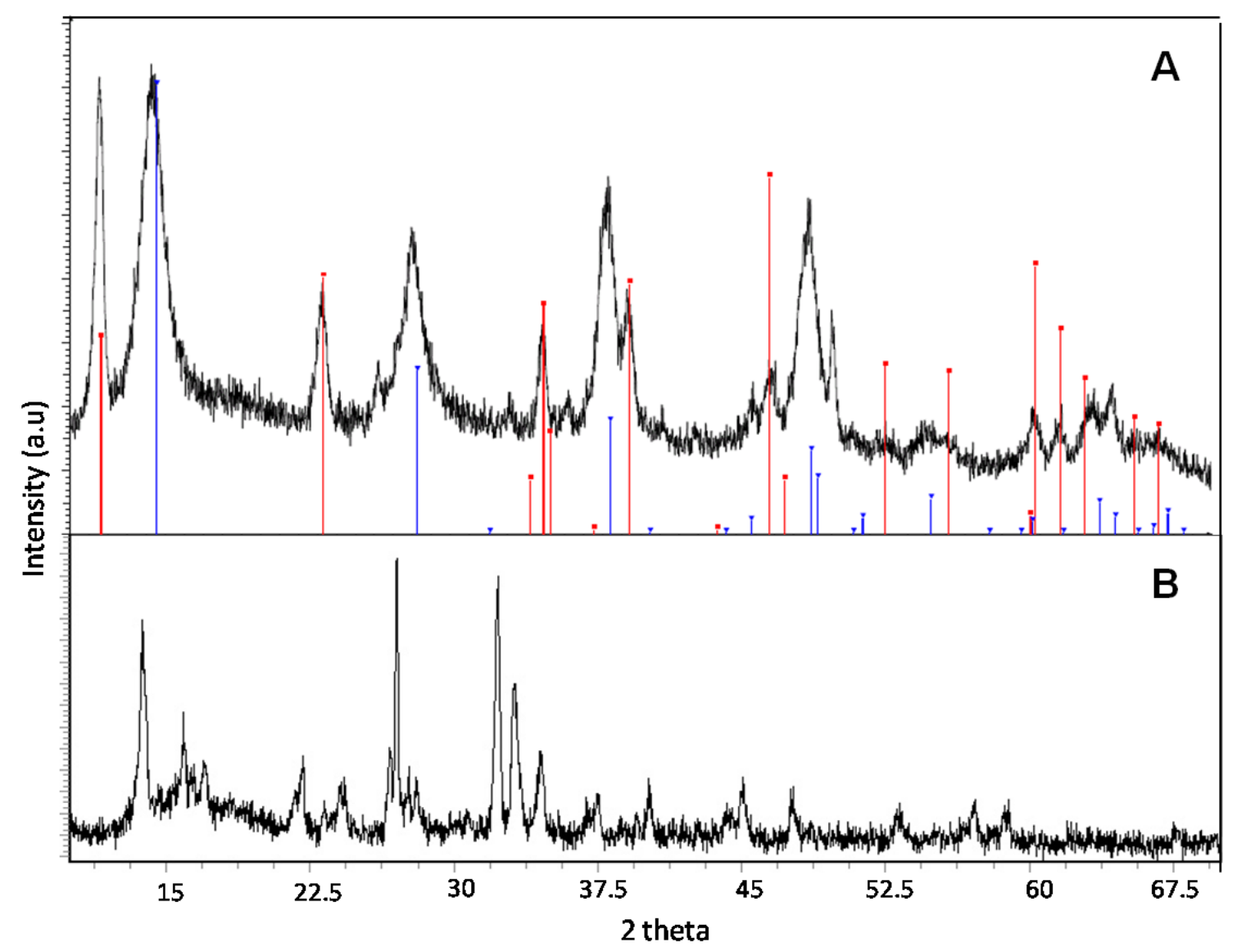

Figure 3. Spectra for X-ray diffraction pattern analysis of LDH (A) and cephradine modified LDH (B).

Table 2. Assignment of various XRD reflections obtained for LDH and cephradine intercalated Mg-Al-LDH.

\begin{tabular}{lcccccc}
\hline \multirow{2}{*}{ Materials } & \multicolumn{6}{c}{ Reflections in $<00 l>$ series } \\
\cline { 2 - 7 } & $2 \theta(\mathrm{deg})$ & $\mathrm{d}(\mathrm{nm})$ & $2 \theta(\mathrm{deg})$ & $\mathrm{d}(\mathrm{nm})$ & $2 \theta(\mathrm{deg})$ & $\mathrm{d}(\mathrm{nm})$ \\
\cline { 2 - 7 } & 11.60 & 0.76 & 23.40 & 0.34 & 34.50 & 0.26 \\
LDH & 2.67 & 3.28 & 5.40 & 1.57 & 7.96 & 1.05 \\
\hline
\end{tabular}

\section{Scanning electron morphological analysis}

Scanning electron microscopy (SEM) was used to elucidate the structural morphology and crystal growth of LDH, which provided useful information about the particle size and bulk strata of the LDH-composite materials. The particles size distribution of LDH depends mostly on the synthesis conditions and varies from few hundred $\mathrm{nm}$ to few micrometer in lateral dimensions [32]. The synthesized Mg-Al-LDH has usually plate-like particle morphology. In Fig. 4, the SEM micrograph of the synthesized LDH shows the particle geometry where the primary plate-like particles are characterized by distinct hexagonal shapes grain with sharp edges (Fig. 4A and C). The highly anisometric nature of these primary particles is also apparent which reflects with varying degree of structural shapes in the images. The lateral dimension of these plate-like particles varies within few micrometer whereas the thickness hardly exceeds few $100 \mathrm{~nm}$. After cephradine intercalation (Fig. 4B), a laminar and ordered structure was produced, therefore, the coarse particles are not observed which is justified by XRD as the amorphous structures are obtained due to lose of crystallinity of Mg-Al-LDH (Fig. 4D). 

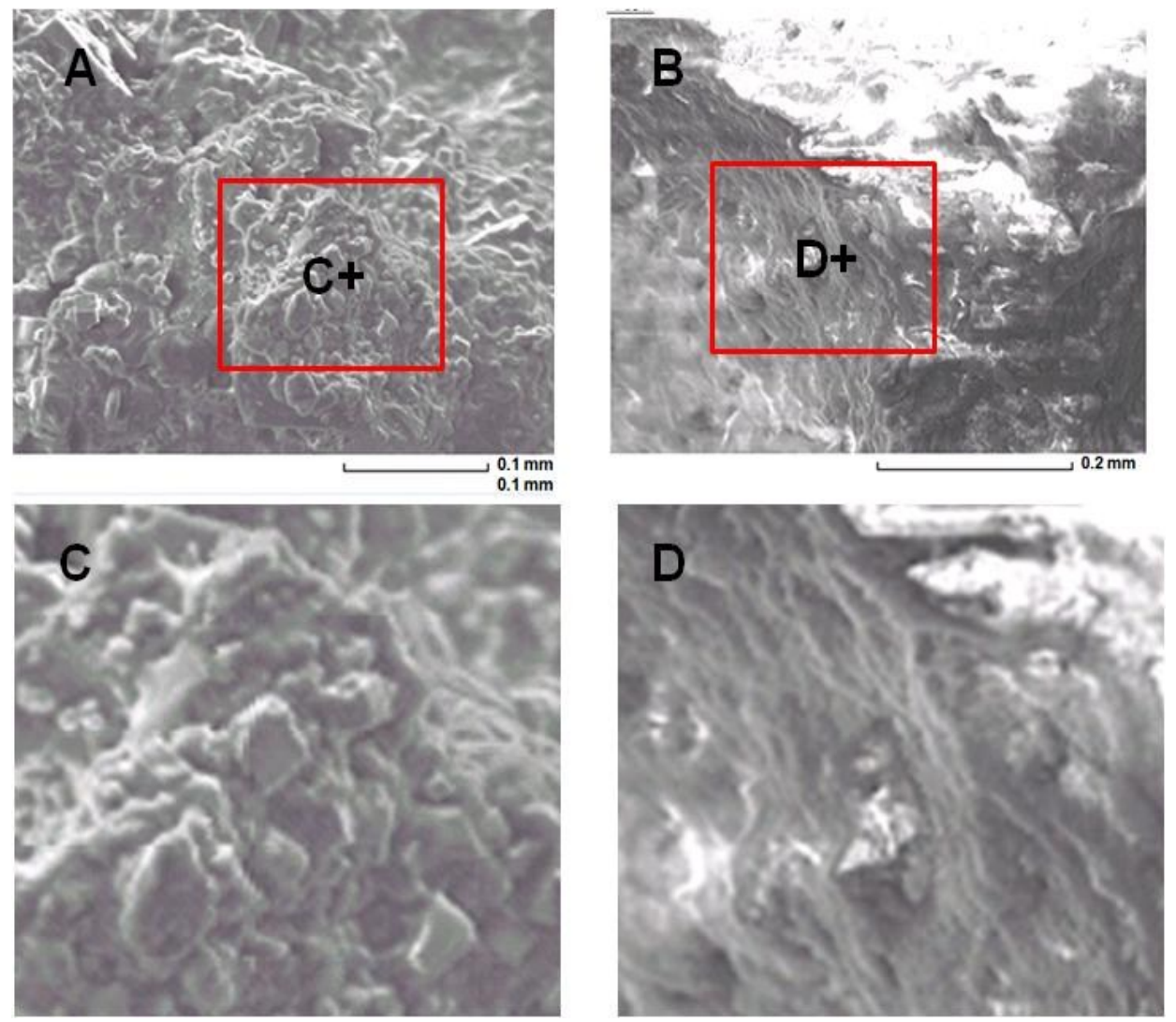

Figure 4. SEM micrographs of synthesized Mg-Al-LDH (A), cephradine modified LDH (B), magnified area of $\mathrm{C}+(\mathrm{C})$ and magnified area of $\mathrm{D}+(\mathrm{D})$.

\section{Conclusion}

In this study, cephradine intercalated LDH was prepared by co-precipitation method. The intercalation phenomenon shows that cephradine drug was modified as cephradine-LDH intercalated composite. The presence of functional groups of cephradine in Mg-Al LDH compounds was confirmed using ATR-IR. The position of the first order basal reflection $<003>$ in the cephradine modified LDH was shifted to a higher d-value indicating an expansion in the interlayer distance. Therefore, we can predict better bio-availability of cephradine and drugs like cephradine in presence of $\mathrm{LDH}$ as an intercalated composite for sustain release and more thermal stability. This study regarding drug intercalated LDH will help pharmaceutical sectors both theoretically and practically.

\section{Acknowledgement}

The authors are grateful to Bangladesh University Grant Commission for financial support to carry out this research work. The authors are also grateful to Mr. Dipok Kumar Sharma for his kind help throughout this work done.

\section{References}

[1] F. Cavani, F. Trifiro, A. Vaccari, Hydrotalcite-like anionic clays: preparation, properties and applications, Catalysis Today. 11(1991) 173-301.

[2] S.P. Newman, W. Jones, Comparative study of some layered hydroxide salts containing exchangeable interlayer anions, Journal of Solid State Chemistry. 148(1999) 26-40.

[3] A. Vaccari, Clays and catalysis: a promising future, Applied Clay Science, 14(1999) 161-198.

[4] S.P. Newman, W. Jones, Synthesis, characterization and applications of layered double hydroxides containing organic guests, New Journal of Chemistry. 22(1998) 105-115. 
[5] P. Yang, J. Yu, Z. Wang, Q. Liu, T. Wu, Urea method for the synthesis of hydrotalcites, Reac. Kinetics Catal. Lett. 83(2004) 275-282.

[6] U. Costantino, F. Marmottini, M. Nocchetti, R. Vivani, New synthetic routes to hydrotalcitelike compounds- characterization and properties of the obtained materials, Europian Journal of Inorganic Chemistry. (1998) 1434-1446.

[7] M. Ogawa, H. Kaiho, Homogeneous precipitation of uniform hydrotalcite particles, Langmuir. 18 (2002) 4240-4242.

[8] G. Mascolo, Synthesis of anionic clays by hydrothermal crystallization of amorphous precursors, Applied Clay Science. 10 (1995) 21-30.

[9] S. Aisawa, S. Takahashi, W. Ogasawara, Y. Umetsu, E. Narita, Direct intercalation of amino acids into layered double hydroxides by coprecipitation, Journal of Solid State Chemistry. 162 (2001) 52-62.

[10] S. Aisawa et al., Intercalation of nucleotides into layered double hydroxides by ion exchange, Applied Clay Science. 28 (2005) 137-145.

[11] A.V. Radha, P.V. Kamath, C. Shikuvakumara, Mechanism of the anion exchange reactions of the layered double hydroxides (LDHs) of $\mathrm{Ca}$ and $\mathrm{Mg}$ with $\mathrm{Al}$, Solid State Sciences. 7(2005) $1180-1187$.

[12] J.C. Dupin et al., Intercalation compounds of Mg-Al layered double hydroxides with dichlophenac: different methods of preparation and physico-chemical characterization, Applied Clay Science. 27(1) (2004) 95-106.

[13] S. Miyata, Physico-chemical properties of synthetic hydrotalcites in relation to composition, Clays and Clay Minerals. 28(1980) 50-56.

[14] A. I. Khan, D. O'Hare, Intercalation chemistry of layered double hydroxides: recent developments and applications, Journal of Materials Chemistry. 12 (2002) $3191-3198$.

[15] T. Kameda, M.Saito, Y. Umetsu, Preparation and Characterisation of Mg-Al Layered Double Hydroxides Intercalated with 2-Naphthalene Sulphonate and 2,6-Naphthalene Disulphonate, Materials Transactions. 47(3) (2006) 923-930.

[16] M. D. Arco et al., Mg, Al layered double hydroxides with intercalated indomethacin: Synthesis, characterization, and pharmacological study, Journal of Pharmaceutical Sciences. 93 (2004) 1649-1658.

[17] J. Tronto et al., In vitro release of citrate anions intercalated in Magnesium aluminiun layered double hydroxide, Journal of Physics and Chemistry of Solids. 65 (2004) 475-480.

[18] P. Beaudot, M.E. De Roy, J.P. Besse, Intercalation of nucleotides into layered double hydroxides by ion exchange. Journal of Solid State Chemistry. 161 (2001) 332-340.

[19] M. del Arco et al., Synthesis and characterization of layered double hydroxide (LDH) intercalated with non-steroidal anti-inflammatory drugs, Journal of Solid State Chemistry. 177 (2004) 3954-3962.

[20] V. Ambrogi, G. Fardella, G. Grandolini, L. Perioli, Intercalation compounds of hydrotalcitelike anionic clays with anti-inflammatory agents-I. Intercalation and invitro release of ibupfofen. International Journal of Pharmaceutical. 220 (2001) 23-32.

[21] U. Costantino et al., Hydrotalcite-like compounds as catalysts in liquid phase organic synthesis I. Knoevenagel condensation promoted by [Ni0.73A10.27(OH)2](CO3)0.135, Journal of Molecular Catalysis A: Chemistry. 195 (2003) 245-252.

[22] S. Vial et al., Nanohybrid-layered double hydroxides/urease material: Synthesis and application to urea biosensor, Materials Science and Engineering. C26 (2006) 387-392.

[23] M. Z. Hussein, A. Yahaya, L.M. Ping, Dye-interleaved nanohybrid: Evan's Blue in the lamella of Mg-Al layered double hydroxide, Dyes and Pigments. 63 (2004) 135-140.

[24] T.J. Gish et al., Transport comparison of technical grade and starch-encapsulated atrazine, Transaction of the ASAE. 34 (1991) 1738-1744.

[25] L. P. Cardoso, R. Celis, J. Cornejo, J. B. Valim, Layered double hydroxide as support for slow release of acid herbicides, Journal of Agricultural and Food Chemistry. 54 (2006) 5968-5975. 
[26] T. S. Stanimirova, G. Kirov, E. Dinolova, Mechanism of hydrotalcite regeneration, Journal of Material Science Letter. 20 (2001) 453-455.

[27] M. Meyn, K. Beneke, G. Legaly, Anionic-exchange reactions of layered double hydroxides, Inorganic Chemistry. 29(1990) 5201-5207.

[28] A. Hashim, (Edited) Advances in Nanocomposite Technology. 15 (2011) 335-360.

[29] J. B. Lambert, H. F. Shurvell, D. Lightner, R. G. Cooks, Introduction to Organic Spectroscopy, Ed., Macmillan Publishing Company, New York, USA, 1987.

[30] M. Z. Hussein, N. Hashim, A. Yahaya, Z. Zainal, Synthesis of Dichlorprop-Zn/Al-hydrotalcite Nanohybrid and its Controlled Release Property, Sains Malaysiana. 40 (2011) 887-896.

[31] C. F. Reny, Mg-Al Layered Double Hydroxide: A Potential Nanofiller and Flame-Retardant for Polyethylene, Dissertation, 2007.

[32] S. Kumar, A. Malas, C. K. Das, Layered double hydroxide modified with linseed compounds for polyurethane elastomer nanocomposites, Polimery. 57 (2012) 18-24. 